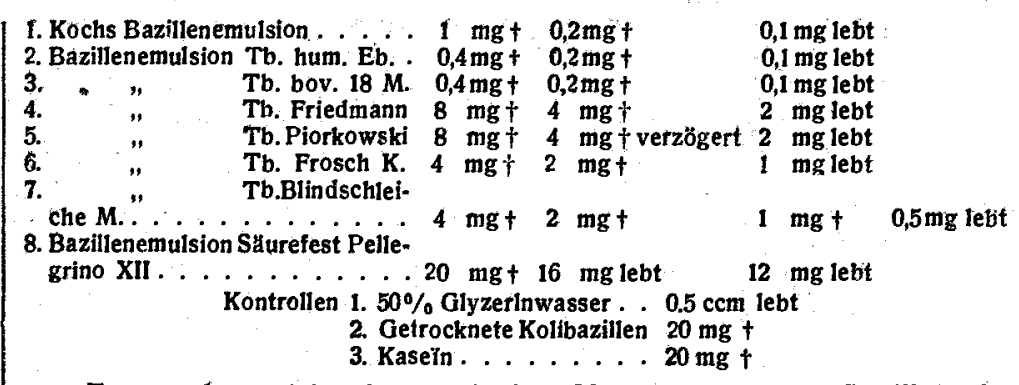

Es ergaben sich also auch bei Verwendung von Bazillensubstanzen, ganz ähnlich wie bei der Prüfung der Tuberkuline, 3 große Gruppen hinsichtlich der Giftwirkung auf tuberkulöse Meerschweinchen: I. die Gruppe der echten, der Warmblütertuberkelbazillen, von denen $0,2 \mathrm{mg}$ tuberkulöse Meerschweinchen töten; II. die Gruppe der Kaltblütertuberkelbazillen, von denen erst $1-4 \mathrm{mg}$ tödlich wirken, also die 5-20fachen Mengen wie bei l., bei denen aber immer noch eine deutliche spezifische Giftwirkung erkennbar ist; III. die rein saprophytischen, säurefesten : Bazillen, wetche deutliche spezifische Giftwirkung nicht mehr entfalten, denn der Tod nach $20 \mathrm{mg}$ Bazillensubstanz Pellegrino darf wohl als unspezifische Proteïnkörperwirkung angesehen werden, zumal auch von getrockneten Kolibazillen und Kaseïn $20 \mathrm{mg}$ bei den hochtuberkulösen Kontrolltieren tödlich wirkten.

Die Schildkrötentuberkelbazillen vor Friedmann und Piorkowski erweisen sich demnach a uch bei Auswertung der Bazillensubstanz, ähnlich wie bei Prüfung der aus ihnen hergestellten Tuberkuline, als. $z$ ur Gruppe der Kaltblütertuberkelbazillen gehörig, stehen aber innerhalbdieser Gruppeden reinen Sapro: phyten bedeutend näher als die Blindschleichen-und Froschtuberkelbazillen.
Aus dem Kaiser Wilhelm-Institut für experimentelle Therapie in Berlin-Dahlem (Direktor: Geh.-Rat A. v. Wassermann).

\section{Vergleichende Prüfung von Bazillenemulsionen verschiedener Tuberkulosestämme.}

\section{Von Dr. W. Dietrich, Oberstabsarzt.}

In D. m. W. 1921 Nr.15 konnte ich über Versuche berichten, welche die Wirkung von Tuberkulinen verschiedener Herkunft auf das tuberkulöse Meerschweinchen zum Gegenstand hatten. Es ergab sich damals unter anderen Beobachtungen, daß im großen ganzen 3 Gruppen zu unterscheiden waren: 1. starkwirkende Tuberkuline von Warmblüterstämmen, 2. mittelkräftige Tuberkuline aus der Gruppe der Kaltblütertuberkelbazillen, zu denen hinsichtlich der Tuberkulinwirkung auch der Friedmannsche und der Piorkowskische Schildkrōtenstamm gezählt werden mußten, und 3. ungiftige, aus rein saprophytischen säurefesten Stämmen.

In Verfolg der damaligen Untersuchungen wurden nun auch Prüfungen mit Bazillenemulsionen der seinerzeit benutzten Stämme angestellt. Die 9 Wochen auf 3\% Glyzerin enthaltendem Hetewasser gezüchteten Bazillen wurden durch einstündiges Erhitzen im Dampftopf abgetötet, dann abfiltriert, der Rückstand mit je 11 physiologischer $\mathrm{NaCl}-$ Lösung auf dem Filter gewaschen und danach im Exsikkator über Chlorkalzium getrocknet. Die völlig trockenen Bazillen wurden dann i11 Mengen von höchstens $200 \mathrm{mg} 2$ Stunden lang in der Reibeschale zermahlen und in abgewogenen Mengen im Achatmörser mit $50 \%$ iger Glyzerinlösung so fein als möglich verrieben.

Unter Berücksichtigung der bei den eingangs erwähnten Versuchen mit den zugehörigen Tuberkulinen ermittelten Verhältniswerte wurden die Emulsionen so gewählt, daB in $1 \mathrm{ccm}$ enthalten waren:

bei Bazillenemulsion $\mathrm{Tb}$. hum. Eber $\ldots \ldots \ldots 4 \mathrm{mg}$ Bazillen-Trockensubstanz

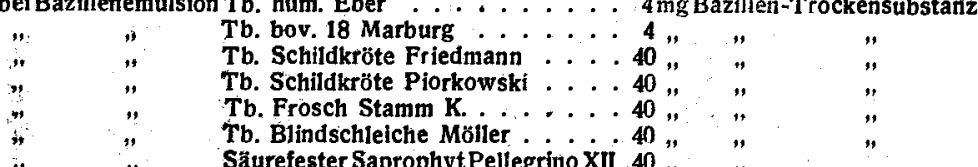

Zum Vergleich wurde ferner eine Kochsche Bazillenemulsion der Höchster Farbwerke herangezogen, von der $1 \mathrm{ccm} 2 \mathrm{mg}$ Bazillenlsubstanz enthielt.

Die Prüfung erfolgte wieder an hochtuberkulösen Meerschweinchen, welche mit $0,5 \mathrm{mg}$ des selır virulenten Stammes $\mathbf{F b}$. hum. Eber subkutan infiziert waren. Die Tierserien wurden erst dann zum Versuch herangezogen, wenn 0,1 Stand. Tuberkulin subkutan die Kontrolltiere in 24 Stunden tötete.

Die Auswertung erfolgte durch intravenöse Injektion im Volumen von jedesmal $0,5 \mathrm{ccm}$.

Das Ergebnis der Untersuchungen ist aus nachstehender Tabelle ersichtlich. 